\title{
The effect of career commitment on academic success among undergraduate baccalaureate nursing students
}

\author{
Kimberly D. Kennel* \\ Division of Nursing, Baptist College of Health Sciences, United States
}

Received: February 14, 2019

Accepted: April 21, 2019

Online Published: April 28, 2019

DOI: $10.5430 /$ jnep.v9n8p59

URL: https://doi.org/10.5430/jnep.v9n8p59

\begin{abstract}
Background: The ability of students, specifically in higher education environments, to persist is a critical determinant of academic success. Student success is especially precarious within programs of nursing, where curricula include clinical, laboratory, and didactic content. Identifying and describing the barriers and facilitators to nursing student persistence provides a blueprint to appropriately use financial and human resources as well as determine the effect student demographic variables has on desiring, attending, or benefiting from academic interventions.

Methods: A descriptive study was used to examine the relationship between the independent variable of self-assessed career commitment, and the dependent variable of academic success among undergraduate nursing students enrolled in a required blended course.

Results: Despite no statistical significance between career commitment and academic success, it should be noted that the failing population had a higher mean score of TTF (Tendency to Foreclose) $M=32.75$ than the passing population $M=31.54$, which may indicate that those students who failed may tend to prematurely commit to nursing as a career choice without a true exploration of possible career choices. The VEC (Vocational Exploration Commitment) $\mathrm{M}=41.59$ was higher in the passing population than the failures with a $\mathrm{M}=37.50$, which may indicate those that passed had explored all career options before committing to nursing as a career choice.

Conclusions: The outcome of this study can guide further research concerning career commitment and career exploration interventions since the process of career commitment is a task for all college students, including those who choose nursing as they identify how they will meet their career goals. Framed by Tinto's Theory of Student Departure, this study assessed the effect of career commitment on academic success among undergraduate baccalaureate nursing students.
\end{abstract}

Key Words: Career commitment, Academic success, Nursing student

\section{INTRODUCTION}

The ability of students, specifically in higher education environments, to persist is a critical determinant of academic success. ${ }^{[1]}$ Student success is especially precarious within programs of nursing, where curricula include clinical, laboratory, and didactic content. The clinical application of didactic content results in a need to persist in both classroom and clinical settings. Thus, barriers and facilitators for the undergraduate nursing student related to persistence may be unique.

Career commitment has been identified by Blustein, Ellis, and Devenis ${ }^{[2]}$ as a potential facilitator to persistence. Career commitment, in this instance, is the process of developing self-generated goals by psychologically attaching to a career

\footnotetext{
*Correspondence: Kimberly D. Kennel; Email: kimberly.kennel@bchs.edu; Address: Division of Nursing, Baptist College of Health Sciences,
} United States.

Published by Sciedu Press 
and identifying oneself with the career. ${ }^{[2]}$ The concept of career commitment describes being certain and self-confident about the individual's choice and experiencing positive feelings regarding vocational future as well as being aware of potential obstacles. ${ }^{[2]}$ Enrollment in a specialized curriculum such as nursing, where course credits will not transfer to other disciplines, may suggest even greater commitment to a specific career choice or occupation. ${ }^{[3]}$ Individuals with a high degree of commitment would likely be prepared to implement their career choice and begin to meet whatever obstacles may impede their attempt to realize their goal. ${ }^{[4]}$

\section{Methods}

\subsection{Significance}

Academic/student success has been defined using traditional measures of academic achievement, such as scores on standardized college entry exams, college grades, and credit hours earned in consecutive terms, which represent progress toward the degree. ${ }^{[5]}$ Assessment of student outcomes or success is an integral part of program evaluation for schools of nursing. ${ }^{[6]}$ The literature identifies many variables or factors that contribute to student success and interventions that may or may not have an effect on success. ${ }^{[7]}$ Individual institutions need to examine their own student populations for potential barriers/facilitators to success. In addition, it is important that increasing numbers of institutions conduct research on student success so patterns and trends might be recognized across similar institutions. ${ }^{[8]}$

\subsection{Theoretical background}

The over-arching theory for this study is Vincent Tinto's Theory of Student Departure. ${ }^{[9]}$ The theory has been used in higher education for more than 40 years and has nearly reached paradigm status in higher education. ${ }^{[10]}$ The theory is foundational, the concepts are well defined, and this theory has been used with other research involving persistence and attrition in higher education. The literature about persistence is based on conceptual frameworks for understanding student departures and was developed to guide the study of attrition and retention in higher education. The theory is by far the most influential model in persistence used to predict or prescribe educational interventions and has been used with empirical research and testing. ${ }^{[10]}$ This theory emphasizes the role of campus-based interactions and integration on persistence and highlights the importance of student experiences on campus. ${ }^{[10]}$ The framework is useful for thinking about the dynamic nature of persistence. ${ }^{[11]}$

The core concepts of this theory, academic and social integration, are noted to have important effects on persistence or dropping out. A student would be at risk for lack of per- sistence or dropping out if they are unable to integrate in either the academic or the social system. ${ }^{[9]}$ Academic and social integration have important direct effects on persistence. What happens to a student after arrival on a college campus may have greater impact on persistence than either the background characteristics or personal commitments to the institution and the goal of graduation. ${ }^{[10,12,13]}$

Seago and associates ${ }^{[14]}$ identified that previous academic achievement, as measured by pre-nursing grade point average (GPA) and science GPA, was a positive predictor of graduation. A conceptual model tested with 738 participants specified four general constructs as predictors of students' success in nursing education: dispositional factors, career value factors, situational factors, and institutional factors. ${ }^{[14]} \mathrm{Ca}-$ reer value factors, as described by Seago and colleagues, ${ }^{[14]}$ mimic those used when discussing career commitment. The survey instrument examined students' perceptions and experiences with the constructs (dispositional, career value, situational, institutional) relevant to their success in completing their nursing education. The career values items loaded on five (subscales) factors (titled job characteristics, autonomy, caring, flexibility, and work style). The subscales for job characteristics and work style had factor loadings, crossloadings, and internal consistency reliability. ${ }^{[15]}$ Identifying the commitment a student has to their career may provide educators with the ability to provide appropriate academic support.

Within Tinto's Theory of Student Departure, ${ }^{[9]}$ the term commitment or goal commitment is identified. Blustein and associates (1989) asserted that by obtaining high levels of commitment, an individual would overcome obstacles and prepare specific objectives to achieve their goals. Career is a term that many individuals use to describe their occupation or job. Career has also been defined as a profession that one trains for and is undertaken as a permanent calling. ${ }^{[16]}$

\subsection{Career commitment}

Career selection may be considered a commitment process. Career commitment, as a construct, can be defined as a process of developing self-generated goals by psychologically attaching to a career and identifying oneself with the career ${ }^{[17]}$ "The extent to which one is committed to a career will be reflected by his or her persistence in pursuing career goals despite obstacles and setbacks that are encountered". ${ }^{[18]}$ The concept of career commitment used in this study refers to being certain and self-confident about the individual's choice and experiencing positive feelings regarding vocational future as well as being aware of potential obstacles as measured by the Commitment to Career Choices Scale (CCCS) instrument. $^{[2]}$ 
Students who perceive the career of nursing as a calling, or having a higher purpose than just a career, may in fact feel such a commitment to their vocational choice that they will make goals to overcome the obstacles or barriers they encounter. The formation of an attachment to a career or vocation derives its theoretical underpinnings from psychological attachment theories developed by John Bowlby. ${ }^{[17]}$ Choosing nursing as a career is a commitment process that brings with it very strong feelings, as sometimes the career commitment process may seem to be guided by family, friends, and/or even spiritual beliefs. Students may in fact believe they were "called" to the career.

The CCCS is a 28-item paper/pencil instrument which uses summed 7-point Likert scale responses to evaluate commitment to a career as a continuum that ranges from uncommitted to highly committed. ${ }^{[2]}$ The CCCS has two subscales: Vocational Exploration and Commitment (VEC) and Tendency to Foreclose (TTF). According to the instrument developers, each construct details an independent dimension or aspect of the commitment process. ${ }^{[2]}$ Potential responses range from "never true about me (1)" to "always true about me (7)" with a neutral "no opinion/not sure" response (4). Possible scores range from 28 to 196.

The CCCS instrument was used to self-assess progress or level in attaining commitment to career choices. Due to the importance of commitment in career development theory, the CCCS was to define, assess, and explore the sequence, constructs, and means by which a person commits to a career choice. ${ }^{[2]}$ The CCCS was developed based on theory and validated with a combination of confirmatory factor analysis and expert raters. Blustein and associates ${ }^{[2]}$ utilized the instrument in two construct validation studies. The constructs within the CCCS include the VEC, which is a dimension that ranges from an uncommitted, exploratory phase to a highlycommitted phase of career exploration and the individual's approach to the commitment process. TTF as a construct explains the individual prematurely committing to a choice without true exploration of potential career options. ${ }^{[2]}$ The CCCS has 19 items that measure VEC and 9 items that measure TTF on a 7-point Likert scale with a Kudar Richardson coefficient of .76 and a correlated $r=.93 .^{[2]}$

The CCCS has been used in multiple studies to assess individuals as they approach the career decision-making process. ${ }^{[4]}$ This process of career commitment is a task for all college students as they identify how they will meet their career goals. ${ }^{[3]}$ Wang and associates ${ }^{[4]}$ used the CCCS to measure career commitment of 184 undergraduate students with a CA of .82 in a study to determine whether self-efficacy could be a mediator for career commitment. The CCCS has also been

Published by Sciedu Press used to determine how parental attachment and separation relationships contribute to the career commitment process. ${ }^{[3]}$

\subsection{Description of study}

The purpose of this descriptive study was to examine the relationship between the independent variable of self-assessed career commitment and the dependent variable of academic success among undergraduate nursing students enrolled in a required blended course in a baccalaureate program. This study aimed to provide data describing where and what evidencedbased interventions would be effective. The hypothesis was that career commitment would have a positive significant effect on academic success. Data describing the concept of career commitment were obtained by self-assessing the constructs of VEC and TTF. ${ }^{[2]}$ The CCCS instrument was used to self-assess progress or level in attaining commitment to career choices (VEC) and the individual's approach to the commitment process (TTF). ${ }^{[2]}$

Academic success, as the dependent variable, was defined as successful completion of an undergraduate blended nursing course and operationalized as the student passing both the didactic and clinical/lab component per the institution's grading scales. The data were gathered from each participant as a pass/fail result of the course at the end of the term. Student background variables were recorded in a demographic form by the students and included demographic responses regarding gender, age, culture/ethnicity, first generation college student, birth order, financial aid status, and whether a member of the immediate family was a nurse or other healthcare professional.

Institutional Review Board (IRB) approvals were secured prior to retrieval of study data from the study site. The study population consisted of volunteer, consented nursing students enrolled in a required blended course within the baccalaureate nursing program of a faith-based private college that serves commuter and residential students within an urban setting in the Mid-South. This blended course has a laboratory/clinical component in addition to the didactic content. The laboratory/clinical component requires each student to provide patient care in addition to completing didactic assignments. The additional required laboratory/clinical activities increase in complexity over the term, which results in the requirements for this course being academically heavy and burdensome. There were 68 students in class on recruitment day, with two students being absent.

\section{RESULTS}

\subsection{Demographics}

Study participants were primarily female (95.4\%), with age ranges of 18-22 (41.5\%), 23-28 (33.8\%), 29-33 (7.7\%), 34- 
$40(9.2 \%)$, and $41-50(7.7 \%)$. The ethnicity of the population was Asian (1.5\%), Black or African American (52.3\%), Hispanic $(3.1 \%)$, White $(36.9 \%)$, and two or more ethnicities $(6.2 \%)$. The birth order in the family included youngest $(29.2 \%)$, middle $(33.8 \%)$, oldest $(26.2 \%)$, and other $(10.8 \%)$. There are missing data for three students who did not complete the demographic information.

The population included $53.8 \%$ first generation college students, and $89.2 \%$ of the participants received financial assistance for their education. The students indicated that $50.8 \%$ have a family member who is a nurse, and $38.5 \%$ have a family member who is a healthcare professional other than a nurse.

\subsection{Study results}

Items from the CCCS were scored according to the author's instructions. The CCCS instrument had six items that were reversed scored. The reversed scored items are as follows: Items \#3, 6, 7, 15, 21, and 24. The CCCS had an overall reliability with a .557 Cronbach's alpha score. Individual item reliability scores range from .511 to .589 . This demonstrates a variance of -.46 to +.32 . These are all within one Standard Deviation (SD) (which would be .55), demonstrating a remarkably stable survey. Instrument reliability for the 19 items of the VEC scale is .859 with item to total reliability ranging from .843 to .864 . This calculates to a .06 to +0.5 range. This is well within the one SD goal (which is .85), identifying the VEC subscale of the CCCS as superior. Instrument reliability for the TTF subscale was calculated as .748 with item to total reliability ranging from .666 to .783. This represents a range of -.72 to +.35 . While wider than the scale, or the VEC subscale, this still falls within the one (SD) range indicative of a stable, reliable survey (which would be .74). Comparing the means of responses to this survey, one sample $t$-test failed to achieve a statistical difference between the two subscales.

Data obtained at the end of the term for the variable academic success included 52 students who had passed the course (persisted) and 16 students who had failed (non-persister). These data were then used to create two groups/populations for comparison. The passing population $(\mathrm{M}=31.54) \mathrm{did}$ not differ significantly from the failure population $(\mathrm{M}=32.75)$ on TTF $(p=.440)$. The $95 \%$ confidence level with zero between the lower (-4.264) and upper (+1.844) limits indicates there would be no difference in the failing and the passing population. The passing population $(\mathrm{M}=41.59)$ did not differ significantly from the failure population $(\mathrm{M}=37.50)$ on Vocational Exploration Commitment (VEC) $(p=.217)$. The $95 \%$ confidence level with zero between the lower $(-2.335)$ and upper $(+10.515)$ limits indicates there would be no difference in the failing and the passing populations (see Table 1).

Table 1. Study variables with means and significance for passing and failing populations

\begin{tabular}{|c|c|c|c|c|}
\hline Study variable & Total population & $\begin{array}{l}\text { Passing population } \\
(\mathrm{n}=52)\end{array}$ & $\begin{array}{l}\text { Failure population } \\
(n=16)\end{array}$ & Significance \\
\hline TTF total score & $\begin{array}{l}\text { 19-43 } \\
\text { (mean 31.82; SD 5.43) }\end{array}$ & $\begin{array}{l}19-43 \\
\text { (mean 31.54; SD 5.70) }\end{array}$ & $\begin{array}{l}25-40 \\
\text { (mean 32.75; SD 4.50) }\end{array}$ & .440 \\
\hline VEC total score & $\begin{array}{l}24-72 \\
\text { (mean 40.63; SD 11.52) }\end{array}$ & $\begin{array}{l}24-72 \\
\text { (mean 41.59; SD 11.49) }\end{array}$ & $\begin{array}{l}24-66 \\
\text { (mean 37.50; SD 11.39) }\end{array}$ & .217 \\
\hline
\end{tabular}

\section{Disscussion/CONCLUSION}

\section{Summary and next steps}

This study examined the concept of career commitment and the relationship to academic success. Nursing student academic success is a complex, dynamic, multidimensional phenomenon influenced by the interaction of personal, academic, and environmental factors. ${ }^{[1]}$ Vincent Tinto's Theory of Student Departure ${ }^{[9]}$ served as the theoretical framework for this study by providing support in addressing the research questions, operationalizing the study variables, and interpreting the results of this study. A theoretical foundation was used to identify potential variables that may or may not influence academic success. ${ }^{[7]}$ The study was comprised of a small sample size which makes it difficult to extrapolate the re- sults. Further studies may be needed to determine whether the CCCS tool is appropriate for the undergraduate nursing population.

The total population was divided into two groups-those that passed the course (passing population) and those that failed the course (failing population) - to determine what variables had a relationship to academic success, which was defined as passing or failing the course. Demographic variables were analyzed to identify any statistical significance between the study groups. Despite no statistical significance between career commitment and academic success, it should be noted that the failing population had a higher mean score of TTF $M=32.75$ than the passing population $M=31.54$, which may indicate that those students who failed may tend 
to prematurely commit to nursing as a career choice without a true exploration of possible career choices. The VEC M = 41.59 was higher in the passing population than the failing population with a $\mathrm{M}=37.50$, which may indicate those that passed had explored all career options before committing to nursing as a career choice.

The process of career commitment is a task for all college students, including those who choose nursing as they identify how they will meet their career goals. ${ }^{[3]}$ Within Tinto's Theory of Student Departure, ${ }^{[9]}$ the term commitment or goal commitment is identified. Blustein and associates ${ }^{[2]}$ asserted that by attaining high levels of commitment, an individual would overcome obstacles and prepare specific objectives to achieve their goals. Lent, Brown, and Hackett ${ }^{[23]}$ suggested that a variety of behaviors may enhance career commitment such as shadowing, mentoring, and co-curricular activities. The pre-nursing student may benefit from shadowing a nurse, seeking volunteer activities on a nursing unit, or receiving mentoring from a senior level student. Müller ${ }^{[24]}$ found that persistent students viewed their education as important to

\section{REFERENCES}

[1] Jeffreys MR. Students' perceptions of variables influencing retention: a pretest and post-test approach. Nurse Educator. 2002; 27(1): 16-19. https://doi.org/10.1097/00006223-200201000-00013

[2] Blustein DL, Ellis MV, Devenis LE. The development and validation of a two-dimensional model of the commitment to career choices process. Journal of Vocational Behavior. 1989; 35(3): 342378. https://doi .org/10.1016/0001-8791(89) 90034-1

[3] Zanardelli G, Shivy VA, Perrone-McGovern KM. Predicting behavioral career commitment of college students with attachment and separation relationships. Journal of Employment Counseling. 2016; 53: 162-173. https://doi.org/10.1002/joec. 12041

[4] Wang N, Jome LM, Haase RF, et al. The role of personality and career decision-making self-efficacy in the career choice commitment of college students. Journal of Career Assessment. 2006; 14(3): 312-332. https://doi.org/10.1177/1069072706286474

[5] Kuh GD, Kinzie J, Buckley JA, et al. Piecing together the student success puzzle: research, propositions, and recommendations: ASHE Higher Education Report. 2011. John Wiley \& Sons.

[6] Reinhardt AC, Keller T, Ochart Summers L, et al. Strategies for success: crisis Management Model for remediation of at-risk students. Journal of Nursing Education. 2012; 51(6): 305-311. PMid:22495924 https://doi.org/10.3928/01484834-20120409-03

[7] Raman J. Nursing student success in an associate degree program. Teaching and Learning in Nursing. 2013; 8(2): 50-58. https: //doi.org/10.1016/j.teln.2012.12.001

[8] Alden KR. Predictors of early academic success and program completion among baccalaureate nursing students. North Carolina State University. 2008; Available from: http://repository.yu.edu. jo/handle/123456789/552917 goal attainment and valued the career or financial outcomes of their education. Changing majors can increase time in school and the total expense of education, which creates a need for a better understanding of influences on career commitment. ${ }^{[3]}$

The administration of institutions of higher learning may also utilize further research to place early warning flags with advisors and faculty to intervene earlier in the pre-nursing part of the curriculum. This warning may provide options for potentially unsuccessful students to explore an alternative education track to achieve success in a different field of study. Career exploration early in high school and the first year of college including job shadowing, volunteering, and nurse mentoring can strengthen the understanding and commitment to pursue a degree. Further studies could be used to determine long term career commitment of practicing nurses and those pursuing further education in a graduate program.

\section{CONFLICTS OF INTEREST DISClOSURE}

The author declares there is no conflict of interest.
[9] Tinto V. Dropout from higher education: a theoretical synthesis of recent research. Review of Educational Research. 1975; 45(1): 89-125. https://doi.org/10.3102/00346543045001089

[10] Burrus J, Elliott D, Brenneman M, et al. Putting and keeping students on track: toward a comprehensive model of college persistence and goal attainment. 2013. Available from: https://www. ets.org/Media/Research/pdf/RR-13-14.pdf https://doi. org $/ 10.1002 / j .2333-8504.2013 . t b 02321 . x$

[11] Tinto V. Leaving college: rethinking the causes and cures of student attrition. University of Chicago Press; 1993.

[12] Pascarella ET, Terenzini PT. Predicting voluntary freshman year persistence/withdrawal behavior in a residential university: a path analytic validation of Tinto's model. Journal of Educational Psychology. 1983; 75(2): 215-226. https ://doi .org/10.1037/0022-0 663.75 .2 .215

[13] Tinto V. Research and practice of student retention: What next? Journal of College Student Retention: Research, Theory \& Practice. 2006; 8(1): 1-19. https://doi.org/10.2190/4YNU-4TMB-22D J-AN4W

[14] Seago JA, Keane D, Chen E, et al. Predictors of students' success in community college nursing programs. Journal of Nursing Education. 2012; 51(9): 489-495. PMid:22849766 https://doi.org/10.3 928/01484834-20120730-03

[15] Seago JA, Wong ST, Keane D, et al. Measuring attributes of success of college students in nursing programs: a psychometric analysis. Journal of Nursing Measurement. 2008; 16(3): 184-200. https://doi.org/10.1891/1061-3749.16.3.184

[16] Career. Merriam-Webster dictionary. 2015. Available from: http: //www.merriam-webster.com/dictionary/career

[17] Blustein DL, Walbridge MM, Friedlander ML, et al. Contributions of psychological separation and parental attachment to the career de- 
velopment process. Journal of Counseling Psychology. 1991; 38(1): 39. https://doi.org/10.1037/0022-0167.38.1.39

[18] Colarelli SM, Bishop RC. Career commitment: functions, correlates, and management. Group \& Organization Studies. 1990; 15(2): 158 https://doi.org/10.1177/105960119001500203

[19] Jeffreys MR. The relationship of self-efficacy and select academic and environmental variables on academic achievement and retention. 1993; (Doctoral dissertation, Columbia University).

[20] Jeffreys MR. Nursing Student Retention. New York, NY: Springer; 2012.

[21] Jeffreys MR. Predicting nontraditional student retention and academic achievement. Nurse Educator. 1998; 23: 42-48. https: //doi.org/10.1097/00006223-199801000-00015

[22] Jeffreys MR. Nontraditional students' perceptions of variables influencing retention: a multisite study. Nurse Educator. 2007; 32(4): 161167. PMid:17627208 https://doi.org/10.1097/01. NNE. 000 0281086.35464. ed

[23] Lent RW, Brown SD, Hackett J. Contextual supports and barriers to career choice: a social cognitive analysis. Journal of Counseling Psychology. 2000; 47(1): 36-49. https://doi.org/10.1037/00 22-0167.47.1.36

[24] Müller T. Persistence of women in online degree-completion programs. International Review of Research in Open and Distance Learning. 2008; 9(2): 1-18. https ://doi.org/10.19173/irrodl.v9 i2. 455 